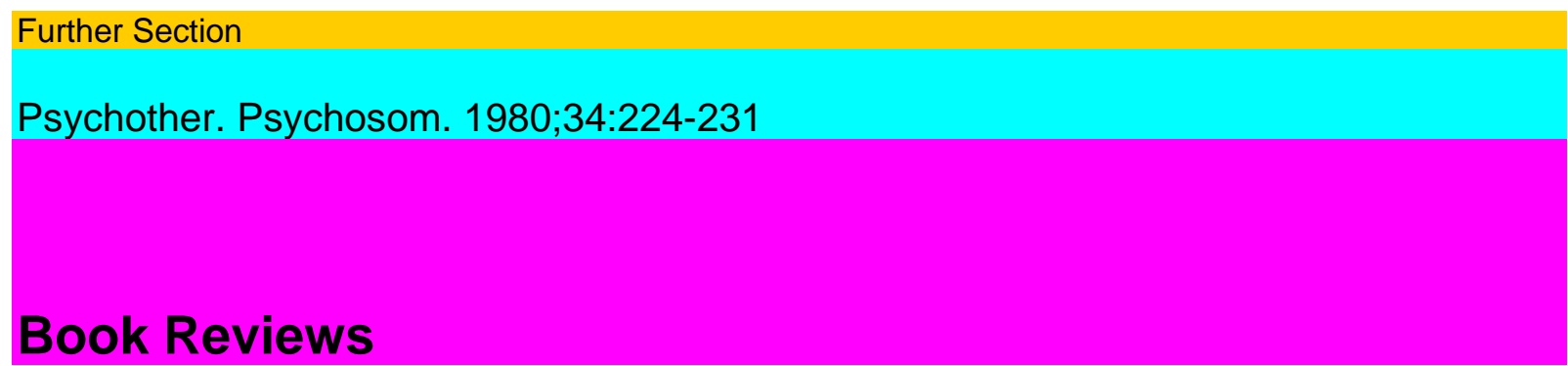

\title{
E. Furman
}

Ein Kind verwaist, Untersuchungen über den Elternverlust in der Kindheit

(Examinations concerning the parents loss in childhood) Klett-Cotta, Stuttgart 1979 310pp.;DM28.-ISBN 3-12-902680-0

Klett-Cotta again published an excellent highly relevant book within the series Concepts of Human Sciences. This book concerns Erna Furman's research work which appeared in the United States under the title A Child's Parent Dies. Furman's work stems from a long-term joint project carried out by child analysts in Cleveland, Ohio. In her foreword, Anna Freud writes:

'Dr. Furman is too modest with regard to the prediction that her and her co-workers' contribution is much higher esteemed than all other earlier publications concerning this topic'

On the basis of the results of the psychoanalytic treatment of 9 children, the psychic consequences of death and mourning become evident. The descriptions are very emphatic, touching and detailed and include a discussion of the due references. The author proves convincingly the thesis that the child's ability to master such a severe loss depends on his psychic 'constitution' on the one hand and on the other hand, mastering of the loss is markedly facilitated by the support on the part of the surviving parent, the siblings and the grand parents.

H. Freyberger, Hannover

Roger A. Stamm and H. Zeier

Die Psychologie des 20. Jahrhunderts, vol. 6

'Lorenz und die Folgen.' Kindler, München 1978. 1217 pp.; DM 220.-

ISBN 3-463-24006-X

Recently, volume VI, entitled 'Lorenz and His Influences', appeared within the well-known, German language encyclopedia: The Psychology of the 20th Century. Preceding volumes were 'Pavlov and His Influences' as well as 'Binet and His Influences'. The main theme with regard to Lorenz includes the subtitles 'Animal Psychology', 'Behavior Research', 'Physiological Psychology'. Konrad Lorenz and Nikolaas Tinbergen are the founders of the field 'Animal behavior research' which is also called 'Ethology'. On the outside cover - next to their pictures the following two statements are presented: 'We are the connecting link between the animal and the truly human man which has been looked for a long time' (Lorenz) as well as 'The man is the single being which is not adapted with regard to his own society' (Tinbergen).

\section{Book Reviews}

225

The two editors' aim is to present mutually the topics 'Ethology' and Physiologically orientated psychology'.

Roger A. Stamm, PhD, born in 1935, is a zoologist who specializes in behavioral research and ecology. His training was completed under the guidance of outstanding teachers (Portmann, Jaspers, Hassenstein, Tinbergen). Stamm has been Chairman and Professor of biology and its didactics in the pedagogical school, Lüneburg (FRG), since 1974. Hans Zeier, PhD, born in 1939, Privat-Dozent of the Institute of Behavioral Science at the Swiss Confederation Technical 
College, is working as behavioral biologist and pedagogue. His work-fields concern the experimental learning research and the physiological psychology. Zeier is distinguished for numerous scientific publications; among others The Dictionary of Learning Theories and Behavioural Therapy (Kindler, 1976) which was compiled by him.

The ethological chapters which are edited by Dr. Stamm include certain specially selected fields. The two initial chapters 'with Regard to the History of Ethology' concern certain historical aspects (G.M. Burghardt, M. Meyer-Holzapfei) as well as chapters about pioneers with regard to ethological research; namely; J.H. Fabre (A. Portmann), J.J. von Uexküll (H. Mislin), K. von Frisch (M. Lindauer), K. Lorenz (I. Eibl-Eibestedt), N. Tinbergen (C.G. Beer) and E. von Hoist (B. Hassenstein).

This historical survey is followed by the topic 'Behavioral Research in Animals'. Firstly, some experts describe the relevant aspects of those animals which represent typical observation objects in research. Secondly, systematic aspects concerning the animal behavior as well as special methodological problems are outlined. The topic 'Ethology of the Man' includes, on the one hand, the results of ethologists' observations in man (R. Schenkel, I. Eibl-Eibesfeldt, R.A. Hinde, W. Schmidt, M. Morath, B. Hassenstein, O. Koenig). These observations also concern those in babies and infants. On the other hand, K.E. Grossmann analyzes the animal as a model concerning the biological and psychological behavior research. W. Schmidbauer makes some remarks concerning the relevance of ethology with regard to psychology and R. Battegay concerning the animal experiment in psychiatry. W. Kalff deals with the field 'The Psychologist's View Concerning the Ethological Opinion of Human Aggression' and M. Schuster with 'Ethology and Ethnology'. On the basis of a book review, particularly with regard to medically orientated readers, it is relatively difficult to completely appreciate the contents which are optimally presented in the Ethology main chapter. The reviewer was very impressed by the outstandingly original manner in which Dr. Stamm realized his editorial work. The chapters with regard to 'Physiologically Orientated Psychology', edited by Dr. Zeier, include two disciplines by which the correlations between physiological and psychological processes are examined. The introduction is presented by the three basically important contributions entitled 'The Development of Physiological Psychology and Psy-chophysiology' (H. Zeier), 'Methods of the Physiological Psychology' (J. P. Huston) as well as 'Methods and Research Problems of Human Psychophysiology' (J.A. Stern). The following chapter 'Neurobiological Bases' includes, without exception, very good and interesting contributions. D. Felix deals with the biochemical bases and the physiological characteristics of the nerve cell and H. Zeier with the bases of the neuroanatomy. J.P. Ewert describes the sensorial systems of recognition, H.H. Kornhuber the motor systems and sensomotor integration as well as A.H. Riesem the ontogenesis of brain and behavior.

Book Reviews

226

The same high quality as in this neurobiological chapter is typical of the following main chapter entitled 'Research Results'. On the basis of this chapter, a survey is given concerning the results which were gained by the physiological psychology and psycho-physiology in dealing with various psychic phenomena. H.H. Kornhuber represents 'Perception and Information Processing'. In the contribution of H. Schulz the fields 'Sleep, Attention and Consciousness' are treated. R.L. Wolfook describes physiological changes which occur at the occasion of meditation exercises. K.H. Delhees' paper concerns the physiological aspects of motivation and emotion. K. Bättig deals with hunger and satiation, E. Endröczi with the role of hormones and neural 
mechanisms by which the sexual behavior is regulated. The learning processes are highly important in T. Ott's and H. Matthies' paper ('Learning and Memory') as well as in J.P. Husten's paper ('Experimental Analysis Concerning Aggressive Behavior'). Finally. A. A. Landauer describes aspects with regard to motor coordination and E. Perret the phenomena 'Brain Dominance' and 'Language from a Neuro-physiological Point of View'. The final contributions of the main chapter entitled 'Physiologically Orientated Psychology' are devoted to certain evolutional philosophical aspects. Here, we would particularly like to mention H. Zeier's contribution 'Evolution of Brain, Behavior and Society'.

In his stimulating final statements, the volumes' coordinator Gerhard Strube, $\mathrm{PhD}$, gives some jsutifications concerning the fact that the topics 'Ethology' and 'Physiological

Psychology/Psychophysiology' were treated in one volume. In the view of the doctor, with regard to the 'Ethology' chapter, there arise some difficulties concerning a full understanding. Fortunately, Dr. Stamm is able to present this complex matter in such an unusually didactical manner that the reader is quickly motivated to deal with the 'Ethology' theme. The second editor, H. Zeier, was able to realize a greatly valuable and optimally selected compilation with regard to the relevant fields 'Physiological Psychology /Psychophysiology'. Furthermore, the reviewer would like to congratulate the two editors because of their excellent cooperation and their splendidly successful attempt to present the two topics within one volume. Therefore, volume VI of this encyclopedia can be just as highly recommended as the previous five volume.

H. Freyberger, Hannover

G. Sterner (ed.)

Piaget und die Folgen (Piaget and His Influence)

Kindler, München 1978. 1201 pp.; DM 220.-ISBN3-463-19010-9

Volume VII of this encyclopedia concerns the topic 'Piaget and his influence' and includes the following subtitles 'Developmental psychology' 'Psychology of thought', 'Genetic psychology'. A first introduction represents the following two statements which are presented on the outside leaf of this book: 'It is a mistake to believe that it is sufficient to deal with a rat for the purpose of making statements with regard to the man' (Jean

Book Reviews

227

Piaget, born 1896 in Neuchâtel, Switzerland) as well as 'The research with regard to genetic cognitive theory makes the attempt to analyze those mechanisms by which cognitive ability develops' (Barbel Inhelder, Professor of Psychology, University of Geneva).

Dr. phil. Gerhard Steiner, born in 1937, pedagogue and psychologist, Professor of Psychology, University of Basle, is the editor of this volume. The research strategies of Steiner concern the questions with regard to cognitive and social development on the one hand as well as cognitive psychological problems on the other hand. According to Steiner, the name of Piaget, the founder of the Geneva school, is closely connected with the history concerning the development psychology. This concerns a 'Monumental work' which has been built up in the last 50 years. By Steiner's opinion, Piaget was greatly successful in outlining his extensive theory, namely: his 'genetic epistemiology' (cognitive theory).

In the first chapter of the volume (pp. 8-74), five authors (M.P. Michiels et al, R.L. Fetz, F. G. Wetzel, J. Piaget, and H. Gardner) present Piaget as a 'genetic cognitive theorist' and seven authors (G.L. Anderson, Ch.K. MacKay, E.D. Neimark, K.F. Riegel, F.H. Hooper et al, Ch.J. Brainers, and E. Wittmanni describe in the second chapter (pp. 87-219) the 'Geneva theory with regard to cognitive development'. That Geneva theory which always regards the learning in 
dependency on certain formulative processes is the focus of the third chapter (pp. 237-306) entitled 'With regard to the building-up of cognitive stuctures'. This chapter is written by four authors (M.C.. Bovet et al, H. Beilin, L. Montada, and J. Bruner et al).

Five authors (W. Doise, A. Colby et al, H. Fend, R.S. Peters, and T.G. Decarie et al.) write the fourth chapter (pp. 321-401) entitled 'Social-cognitive, moral and affective development'. They start from the thesis that the development of intelligence is also dependent on social interactions. The fifth part (pp. 425-488), which is treated by four authors (A. Kun, C. Saarni et al, J.P. Guilford, and J.F. Wohlwill), includes the presentation of the personality concept with special regard to the development. The chapter's title is the following: 'Motivation, cognitive styles, creativity'.

In the sixth part (pp. 503-584) five authors (G. Meili-Dworetzki, R. Meili, D.P. Ausubel et al, J. Langer et al, and D. Elkind) present 'Piaget in the historical-systematic comparison'. In the seventh part (pp. 595-709), six authors (H. Aebli, T.B. Seller, H. Skowronek, T. Mischel, D.E. Berlyne, and J.S. Carlson) are concerned to confront Piaget's theory with some basic questions with regard to the developmental theory. The eighth part (pp. 729-835), entitled 'Perceiving and thinking in a cognitive view', is realized by six authors (J. Voneche, K.G. O'Bryan, J.S. Meyer et al, U. Neisser, A. Paivio, and C. Voelin et al). This chapter starts from the concept 'Cognitive change' towards the cognitive psychology which should be particularly concerned with that which may happen between the reception of a stimulus and the corresponding reaction to it. The ninth part (pp. 849-951) is written by six authors (P. Mounoud, S.G. Paris et al, S.R. Palef, F. Klix, H.A. Simon et al, and G. Cellebrier). The field 'memory', one of the basic processes of modern psychology, is the focal point of the main topic: 'Information assimilation in the man, memory and solving of problems'. Finally, the tenth part (pp. 976-1160), which was written by ten authors (J.P. Bronckart et al, H.G. Furth, M.F. Garrett et al, A.R. L·uria, P.M. Greenfield, J.B. Carroll, E.A. Lunzer, W. Klein, R.O. Feedle, B. Inhelder), deals with the various aspects of language; particularly in the sense of a kind of language behavior with which the socio-linguist is concerned.

Book Reviews

228

In his epilogue the coordinator of the whole encyclopedia, Gerhard Strube (Munich), $\mathrm{PhD}$, stipulates that the 'genetic psychology has its main field there where the developmental psychology and the psychology of the cognitive processes overlap'. According to Strube, Piaget's psychology represents, above all, an empirically proved theory with regard to the mental development of the child. In summary, Strube characterizes 'the cognitive psychology by its interest in the inner processes of the human in the sense of a self-regulating information working system; furthermore: by her aim, these processes to stimulate and to describe in action plans analogous to computer programs'.

Initially, the editor of this volume, Gerhard Steíner, speaks of the 'monumental work' of Piaget. Following the study of this book, the reviewer has had the further association of a 'mammoth work' which was realized by Steiner in an outstanding manner. An editor function like this one can not be surpassed: it is an optimal combination of scientifically based facts on the one hand and easily understandable, practically based presentations with regard to the reader on the other hand. The entry into the very complex subject of this book is considerably facilitated by Steiner for he introduces each of the ten chapters in a very informative way. However, this book is not only an outstanding one with regard to the editorial work and the quality of the contributions but also concerning the outward appearance including the impressive illustrations. 
H. Freyberger, Hannover

Lazarus, Arnold A. Verhaltenstherapie um Übergang.

Breitbandmethoden für die Praxis.

Reinhardt, München 1978. 193 pp.; DM 32.50.

ISBN 3-497-00813-3.

The well-known book 'Behavior therapy and beyond' by Arnold Lazarus, the famous practitioner in behavior therapy, is now published in German. The book aims at a broadening of the base of conventional behavior therapy. In eleven chapters it provides an interesting combination of different techniques. After an introduction concerned with definition and origin of behavior therapy, styles of interviewing are discussed, stressing a personalistic viewpoint. Projective techniques aiming at patient's relaxation, desensitization, habituation, as well as role playing and assertive training are other subjects. Also therapy of sexual dysfunctions, cognitive restructuring, methods of therapeutic groups and finally problems of behavioral treatment of children are dealt with. The book offers a detailed description of a lot of very important treatment methods and gives advice for application. In all it's a book for practitioners in psychotherapy, which presents a new kind of behavior therapy by emphasizing the individual needs of the clients. At last this important book of behavior therapy, which was first published in 1971, was published in German, but the translation is often very stumbling, it should be revised as soon as possible.

H.-W. Künsebeck, Hannover

Book Reviews

229

C.P. Kim ball and A.J. Krakowski (eds.)

The Teaching of Psychosomatic Medicine and Consultation-Liaison

Psychiatry

Reactions to Illness. 4th Congr. Int. Coll. Psychosom. Med., Kyoto 1977

Bibliotheca Psychiatrica, No. 159

Karger, Basel 1979. X + 190 pp., 13 fig., 23 tab., SFr. 83.-/ DM 99.-/

approx. US $\$ 49.75$

ISBN 3-8055-2955-4

This volume, mostly containing papers presented at the 4th Congress of the International College of Psychosomatic Medicine in Kyoto, 1977, addresses two issues: 'Teaching of the consultationliaison process' and 'Reactions to illness'.

After an introductory chapter by Krakowski describing the scope, aims and function of consultation-liaison psychiatry in North America in the current decade, several contributions \{Greenhill, Kimball, Iwasaki, Bastiaans) are devoted to general principles of teaching the psychosomatic approach in the hospital to students and physicians. More specific topics, in the area of liaison psychiatry, are: attitudinal learning (Schüffel); Balint group work with students (Freyberger); management of attitudes related to culture, age and sex (Hertz, Greenhill); confidentiality in the consultation-liaison process (Kimball); liaison psychiatry in the hemodialysis center (Levy), and the geriatric consultation (Krakowski).

More general and theoretical considerations are presented with regard to the relationship of illness to development states (Gaddini) and agression (Musaph). The different aspects of pain are exposed in a very well-documented and comprehensive study of Ramsy, Rehabilitation in general (Aitken) and in the elderly (Rees) is introduced as a growing necessity with many still unsolved problems. 
A volume, composed of contributions by so many different authors, inevitably suffers from some heterogeneity and a number of reiterations. These shortcomings are largely compensated by the very valuable information offered on a lot of problems arising in the actual practice of psychosomatic medicine.

R. Pierloot

P. Hahn (ed.)

Die Psychologie des 20. Jahrhunderts

Vol. 9, Ergebnisse für die Medizin. I. Psychosomatik. Kindler, München 1979. 1072 pp., DM 220.-ISBN 3-463-24009-2

The extensive field 'Psychosomatics' is the topic of volume 9 of the encyclopedia 'The Psychology of the Twentieth Century'. The editor is Dr. Peter Hahn, born in 1931, Internist and Psychoanalyst, Professor and Chairman, Department of Medicine II (General Clinical and Psychosomatic Medicine), University of Heidelberg, Heidelberg (FRG). In the case of Book Reviews

230

Hahn and in Germany, the combination of medicine and psychoanalysis is a relatively frequent one for in Germany psychosomatic medicine does not stem from psychiatry but from medicine. The inherent pioneers were Paul Christian, Arthur Jores and Thure von Uexküll. Hahn, a pupil of Christian, feels himself particularly connected to the great psycho-logico-medical tradition which is characteristic of Heidelberg.

Volume 9 consists of the following main chapters: 'Methodology' (pp. 9-116), 'Psychosomatic work models' (pp. 117 - 298), 'Problems concerning psychosomatic diagnosis’ (pp. 299-316), 'Psychosomatic diseases in specialized fields' (pp. 317-806), 'Therapy' (pp. 807-1002) as well as 'Process and success control' (pp. 1003 -1022).

The main chapter 'Methodology' is divided into two subchapters 'Methodological considerations' (pp. 9-39), including contributions by R. Vogt and H. Wottawa, as well as 'Special methodological dispositions in psychosomatic research'. The following aspects are treated in the latter subchapter: 'Clinical and biographical procedures' (P. Hahn), 'Psychophysiological methods' (H Mayer), 'Test psychology' (S. Hehl), 'Learning theory' (H. Fer-ner), 'Psychoanalysis' (R. Vogt) and 'Socio-medical epidemiology' (E. Nüssei).

The high competence of the authors does not only concern the latter contributions but also the following subchapters.

Within the main chapter 'Psychosomatic work models', the introduction 'The model concept in psychosomatic medicine' (R. Vogt) is followed by a presentation of the interpretation possibilities with regard to psychosomatic processes. On the one hand, four psychoanalytical models are treated: the earlier and later developments of the conversion model (P. Hahn), the socalled specific model (L. Janus), the theory with regard to the somatization and resomatization in the sense of M. Schur (M. v. Rad) as well as the object psychologically orientated models of the French school (S. Stephanos). Furthermore, the following fields are discussed: recent models with regard to cybernetics (M. Urban) and stress research (H Maier) as well as behavioral therapeutical concepts $(H$. Ferner $)$ and sociopsychological disposition $\left(\AA^{\wedge}\right.$. Brede).

The special clinical part is introduced by critical considerations regarding psychosomatic diagnostics (H. Studt). The first contribution within the main chapter 'Psychosomatic diseases in specialized fields' represents 'General medicine' (W. Wesíack). Following it, various fields of medicine are treated systematically: 'Cardiovascular diseases' (P. Hahn), 'Lung diseases' (HH. Studt), 'Gastrointestinal, liver and bile diseases' (H. Freyberger), 'Renal diseases' (P. Vollrath), 
'Metabolic diseases' (A. Reindell), 'Hormonal diseases' (M. Neubauer), 'Infectious diseases' (J.M. Herrmann), 'Rheumatic diseases' (J.M. Herrmann), and 'Oncological diseases' (M. v. Rad). Following the medical field, the further disciplines are presented: 'Neurology' (F. Lamprecht), 'Anesthesiology' (D. Langeri), 'Surgery' (H Freyberger) and 'Gynecology' (W. Eicher, D. Jürgensen). Finally, the following fields are treated: 'Orthopedics' 'Disease of the ear,

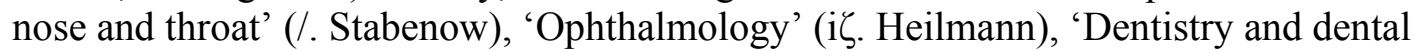
orthopedics' (D. Herrmann), 'Pediatrics' (H. Steffen), 'Dermatology' (/. Rechenberger), 'Andrology' (H.G. Rechenberger) and 'Geriatrics' (H. Radebold).

Similar to the latter main chapter 'Psychosomatic diseases in specialized fields', the main chapter 'Therapy' also includes clear evidence with regard to specific psychosomatic therapy strategies which are so relevant when dealing with psychosomatic patients. In this connection the following topics are presented: 'Training methods' (E. Petzold), 'Adolescent the-

Book Reviews

231

rapy’ (B. Vogt-Heyder), 'Group therapy' (H. König), 'Family therapy’ (M. Winching) and 'Social therapy' (F. Haag). The inpatient therapy is presented on the basis of the following three parts: 'Active clinical methods' (E. Petzold), 'Analytico-clinical points of view' (A. Sellschopp), and 'Specific conditions of psychotherapeutic cures' (H. Neuri).

The final contribution concerns that of R. Göllner and is entitled 'Control of therapeutic course and success rate'. The catamnesis research and presentation of the therapeutic results concerning the most important psychosomatic diseases are considered here.

T. This extensive book represents a standard work of psychosomatic medicine as the consequence of Hahn's sovereign editor function. On the basis of this book

the great relevance of psychosomatic medicine is strongly confirmed. The high quality of this book is particularly due to the highly informative content and the very extensive oversight of thematical structure which excludes disturbing overlappings. In the view of the reviewer there does not exist today one book in the field of psychosomatic medicine in which such comprehensive information is given.

H. Freyberger

Hannover 